Subscriber access provided by Caltech Library

\title{
Environmental Processes
}

\section{Distribution of extracellular flavins in a coastal marine basin and their relationship to redox gradients and microbial community members}

Danielle Monteverde, Jason Sylvan, Christopher Suffridge, J. Jotautas Baronas, Erin Fichot, Jed Fuhrman, William M. Berelson, and Sergio Sanudo-Wilhelmy

Environ. Sci. Technol., Just Accepted Manuscript • DOI: 10.1021/acs.est.8b02822 • Publication Date (Web): 27 Sep 2018

Downloaded from http://pubs.acs.org on September 27, 2018

\section{Just Accepted}

"Just Accepted" manuscripts have been peer-reviewed and accepted for publication. They are posted online prior to technical editing, formatting for publication and author proofing. The American Chemical Society provides "Just Accepted" as a service to the research community to expedite the dissemination of scientific material as soon as possible after acceptance. "Just Accepted" manuscripts appear in full in PDF format accompanied by an HTML abstract. "Just Accepted" manuscripts have been fully peer reviewed, but should not be considered the official version of record. They are citable by the Digital Object Identifier (DOI®). "Just Accepted" is an optional service offered to authors. Therefore, the "Just Accepted" Web site may not include all articles that will be published in the journal. After a manuscript is technically edited and formatted, it will be removed from the "Just Accepted" Web site and published as an ASAP article. Note that technical editing may introduce minor changes to the manuscript text and/or graphics which could affect content, and all legal disclaimers and ethical guidelines that apply to the journal pertain. ACS cannot be held responsible for errors or consequences arising from the use of information contained in these "Just Accepted" manuscripts. 


\section{Distribution of extracellular flavins in a coastal}

\section{2 marine basin and their relationship to redox}

\section{3 gradients and microbial community members}

4 Danielle R. Monteverde ${ }^{\mathrm{a}_{\dagger}}{ }^{*}$, Jason B. Sylvan ${ }^{\mathrm{b}}$, Christopher Suffridge $\mathrm{c}_{\dagger}^{\mathrm{f}^{*}}$, J. Jotautas Baronas $\mathrm{a}_{\dagger^{*}}$,

5 Erin Fichot ${ }^{\mathrm{c}}$, Jed Fuhrman ${ }^{\mathrm{c}}$, William Berelson ${ }^{\mathrm{a}}$, Sergio A. Sañudo-Wilhelmy ${ }^{\mathrm{a}, \mathrm{c}}$

$6{ }^{\text {a }}$ Department of Earth Sciences, University of Southern California, Los Angeles, California,

7 USA

$8 \quad{ }^{\mathrm{b}}$ Department of Oceanography, Texas A\&M University, College Station, Texas, USA

$9{ }^{\mathrm{c}}$ Department of Biological Sciences, University of Southern California, Los Angeles, California,

10 USA

11 *Address correspondence to Danielle Monteverde, dmonteverde@caltech.edu, P: 626-395-6123,

12 F: 626-395-1995

$13 \nmid$ Present addresses:

14 Danielle R. Monteverde, Division of Geological and Planetary Sciences, California Institute of

15 Technology, Pasadena, California, USA

16 Christopher Suffridge, Department of Microbiology, Oregon State University, Corvallis, Oregon,

17 USA

18 J. Jotautas Baronas Department of Earth Sciences, University of Cambridge, Cambridge, United

19 Kingdom 


\section{Abstract}

22 The flavins (including flavin

23 mononucleotide $[\mathrm{FMN}]$ and riboflavin $[\mathrm{RF}])$

24 are a class of organic compounds

25 synthesized by organisms to assist in critical

26 redox reactions. While known to be secreted

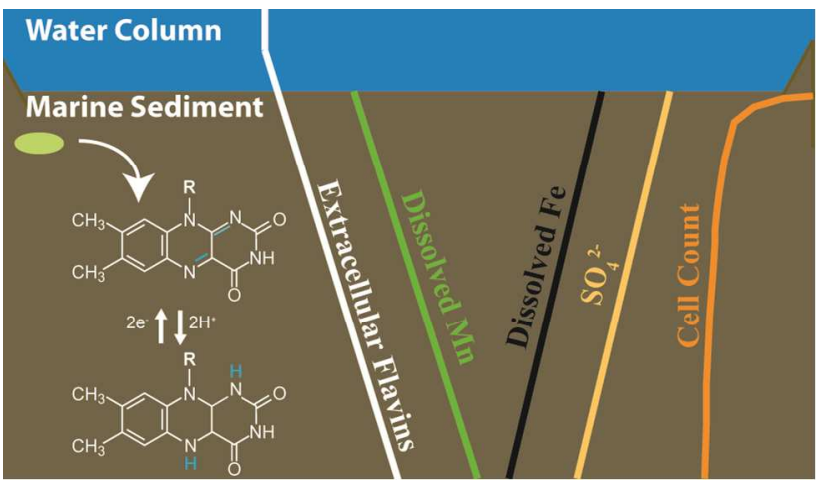

27 extracellularly by some species in laboratory-based cultures, flavin concentrations are largely unreported in the natural environment. Here, we present pore water and water column profiles of

29 extracellular flavins (FMN and RF) and two degradation products (lumiflavin and lumichrome)

30 from a coastal marine basin in the Southern California Bight alongside ancillary geochemical

31 and 16S rRNA microbial community data. Flavins were detectable at picomolar concentrations

32 in the water column (93-300 pM FMN, 14-40 pM RF) and low nanomolar concentrations in pore

33 waters (250-2070 pM FMN, 11-210 pM RF). Elevated pore water flavin concentrations

34 displayed an increasing trend with sediment depth and were significantly correlated with the total 35 dissolved Fe (negative) and Mn (positive) concentrations. Network analysis revealed a positive 36 relationship between flavins and the relative abundance of Dehalococcoidia and the MSBL9

37 clade of Planctomycetes, indicating possible secretion by members of these lineages. These

38 results suggest that flavins are a common component of the so-called shared extracellular

39 metabolite pool, especially in anoxic marine sediments where they exist at physiologically-

40 relevant concentrations for metal oxide reduction. 


\section{Introduction}

45 Flavins are organic molecules that represent the largest class of essential biological 46 catalyzers, rivaled only by iron in the number of unique enzymes they bind. ${ }^{1-2}$ Flavins - flavin

47 mononucleotide (FMN), flavin adenine dinucleotide (FAD), and their biosynthetic precursor 48 riboflavin $(\mathrm{RF})$ - contain a nitrogen heterocycle isoalloxazine moiety, which is utilized in redox

49 reactions to complete both single and double electron and hydrogen transfers critical for

50 catabolic and anabolic reactions. ${ }^{3}$ Their catalytic utility extends to a diverse set of biochemical

51 reactions including DNA photorepair, halogenation and dehalogenation, antibiotic synthesis,

52 dioxygen activation, quorum signaling, light sensing photoreceptors, and electron bifurcation. ${ }^{3-6}$

53 In addition to critical requirements inside the cell, some metal-reducing microbial species are

54 known to actively secrete flavins into the shared extracellular metabolite pool in which they can

55 aide in extracellular electron transfer (EET) to insoluble metal oxides. ${ }^{7-9}$

56 Flavins are powerful reductants possessing low redox potentials $\left(\mathrm{E}^{\prime}=-216 \mathrm{mV}\right.$ for

$57 \mathrm{FMN} / \mathrm{FMNH}_{2}$ and $-208 \mathrm{mV}$ for $\mathrm{RF} / \mathrm{RFH}_{2}$ versus the standard hydrogen electrode ${ }^{10}$ ), making

58 them well suited to reduce Fe and Mn oxides commonly found in natural waters and marine

59 sediments as well as redox active radionuclides ${ }^{11}$ and toxic metals in contaminated

60 environments. ${ }^{11-12}$ Studies exist on the ability of the metal-reducing organism Shewanella, ${ }^{7,13}$ to

61 secrete flavins to aid in EET by acting either as an electron shuttle or as a flavocoenzyme that

62 activates an outer membrane cytochrome (OMC) enabling electron transfer directly to insoluble

63 metal oxides. ${ }^{9,12,14}$ The distribution of organisms capable of EET appears to be widespread, ${ }^{15-16}$

64 however flavins are not a universal requirement for EET and it is unclear whether flavin

65 secretion is a common strategy, or unique to only a few organisms. Most microorganisms as well

66 as fungi and plants can synthesize flavins de novo, ${ }^{17}$ but it is unclear how many actively secrete 
67 them (as opposed to release from cell lysis) outside the cell. Flavin secretion has been shown in

68 some Pseudomonas, Escherichia, and Geothrix species as well as the gram-positive Bacillus (sp.

69 WS-XY1), and yeast (Pichia stipitis). ${ }^{8,18-19}$ Flavin secretion is also a well-known plant stress

70 response to Fe-limiting conditions. ${ }^{20}$ Therefore it is possible that flavins may represent a

71 common component of the redox active humic load in aqueous environments. ${ }^{21}$

72 Despite their vital role in cellular metabolism, utility in EET, bioremediation applications,

73 and implications for the biogeochemical cycling of redox-sensitive elements, environmental

74 concentrations of flavins remain largely unmeasured. One reason for the absence of

75 environmental flavin measurements is their trace concentration and structural lability. Flavins are

76 known to rapidly photodegrade, forming the degradation products lumichrome (LC) and

77 lumiflavin (LF). ${ }^{22}$ Furthermore, the few studies that have attempted to investigate environmental

78 flavin concentrations via fluorometric techniques have found them to be in trace concentrations

79 (pM range), and therefore a preconcentration step is required prior to quantification. ${ }^{23}$ Here we

80 present environmental concentrations of the flavins (FMN and RF) and their degradation

81 products LC and LF measured in the water column and pore waters of a coastal marine

82 environment in San Pedro Basin (Figure S2) using a newly adapted, compound-specific, High

83 Performance Liquid Chromatography Mass Spectrometry (LC/MS) method. We compare pore

84 water flavin profiles in sediment cores, extending down to $40 \mathrm{~cm}$, to concentrations of classic

85 indicators of geochemical zonation (total dissolved $\mathrm{Fe}, \mathrm{Mn}$, and $\mathrm{SO}_{4}{ }^{2-}$ ), microbial cell

86 quantification, and 16S rRNA microbial community composition from 11 sediment horizons.

87 We also use network analysis to identify taxonomic groups that are correlated with flavin

88 concentrations in sediments. The sediment flavin quantifications were complemented with water

89 column measurements from surface to 800 meters. Our results show that flavins are indeed 
90 present in the marine environment, especially in anoxic marine sediments in which they appear

91 to be a common component of the shared extracellular metabolite pool. They also point to

92 lineages that display positive interactions with flavins, allowing for hypothesis generation about

93 flavin production in sediments.

\section{Materials and Methods}

95 Study Site and Sample Collection.

96 San Pedro Basin (SPB) is located within the Southern California Bight and is bounded by

97 Los Angeles, California to its northeast and Santa Catalina Island to its southwest (Figure S2).

98 The San Pedro Ocean Time series station (SPOT) is located in the center of the basin $\left(33^{\circ} 33^{\prime} \mathrm{N}\right.$,

$99118^{\circ} 24^{\prime} \mathrm{W}$ ), where monthly sampling of the water column for biologic and hydrographic

100 parameters has been conducted since $1998 .^{24}$ The basin is approximately $900 \mathrm{~m}$ deep and silled

101 at $740 \mathrm{~m}$, with suboxic bottom waters which experience high seasonal particulate inputs resulting

102 in pore water $\mathrm{O}_{2}$ and $\mathrm{NO}_{3}{ }^{-}$concentrations falling below detection within a few $\mathrm{mm} .{ }^{25}$

103 Water column samples were collected from SPOT on April 4, 2014. Samples were

104 collected from 8 depths with a CTD rosette (Sea-Bird electronics, Bellevue WA, USA) fitted

105 with 12-L Niskin bottles (General Oceanics, Miami, FL, USA). Samples were immediately

106 filtered with $0.2-\mu \mathrm{m}$ Supor ${ }^{\circledR}$ PES Membrane filters (Pall Laboratory, Port Washington, NY,

107 USA) and stored frozen at $-20^{\circ} \mathrm{C}$ in amber bottles. Sediment cores were collected on September

1089 9, 2014 with an Ocean Instruments, Inc. (San Diego, CA, USA) MC-400 multicorer containing

$1099.5 \mathrm{~cm}$ diameter core liners. ${ }^{26}$ Cores were initially assessed for clear sediment water interface,

110 measured and described, and assigned to pore water or solid phase analysis. The sediment

111 height in collected cores ranged from $38-47 \mathrm{~cm}$ with $12-3 \mathrm{~cm}$ of overlying water. All cores were

112 stored on board ship in an ice bath protected from light and transported to the laboratory cold 
113 room maintained between $5-10^{\circ} \mathrm{C}$ for sampling. Cores assigned to pore water collection were

114 sampled at 0.5-1 cm depth intervals using rhizon soil samplers (Rhizosphere Research Products,

115 Wageningen, Netherlands; $0.2-\mu \mathrm{m}$ pore size filters) and $30 \mathrm{~mL}$ plastic Norm-ject巴 syringes (Air-

116 Tite Products Co., Inc., Virginia Beach, VA, USA) which had been acid-cleaned and methanol-

117 rinsed. Each rhizon syringe collected between $20-30 \mathrm{~mL}$ of pore water which was pooled with

118 the syringe from the same depth on the other side of the core to bring a total sample volume to

$11940-60 \mathrm{~mL}$ for each sediment depth. Water was then allocated into separate trace metal and flavin

120 sample bottles. Flavin samples were frozen in acid-cleaned and methanol-rinsed high-density

121 polyethylene (HDPE) amber bottles until analysis. Samples were protected from light

122 throughout sample processing. The aliquots for trace metals were stored in trace metal-cleaned

123 HDPE bottles and acidified with Optima-grade $\mathrm{HNO}_{3}{ }^{-}$(Fisher Chemical, Canoga Park, CA,

124 USA) to a $\mathrm{pH}<2$ following standard trace clean techniques.

Cores assigned to solid phase analysis were stored in a cold room protected from light at

$1265-10^{\circ} \mathrm{C}$ and sectioned within 4 days of collection using a core extruder and processed for cell

127 counts and 16S rRNA molecular community analysis, described further below. Cores were

128 sectioned at $0.5-2 \mathrm{~cm}$ depth intervals, each sediment section was homogenized and samples were

129 collected from the center of the core to avoid any artifacts from the core liner. Samples for

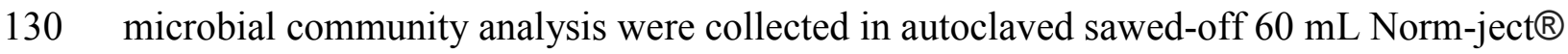

131 syringes (Air-Tite Products Co., Inc., Virginia Beach, VA, USA) that were flash frozen with

132 liquid nitrogen and stored at $-20^{\circ} \mathrm{C}$ until analysis. For samples preserved for biomass

133 enumeration via cell counts, $2 \mathrm{mg}$ of sample was added to $15 \mathrm{~mL}$ centrifuge tubes with $8 \mathrm{~mL}$ of

134 filtered 2\% paraformaldehyde. After incubation for 17 hours, the suspension was spun down and 
135 the pellet rinsed twice with phosphate buffered saline (PBS) and finally resuspended in $8 \mathrm{~mL}$ of $13650 / 50$ methanol/PBS. Cell count samples were stored at $4^{\circ} \mathrm{C}$ until analysis.

\section{Analytical Methods}

\section{Solid Phase Sample Extraction of Flavins}

Samples (water column and pore waters) were preconcentrated using a solid-phase extraction (SPE) as previously developed for B vitamins. ${ }^{27}$ Briefly, SPE consisted of passing the sample

141 volume over a pre-conditioned column packed with HF Bondesil- $\mathrm{C}_{18}$ Resin (Agilent

142 Technologies, Santa Clara, CA, USA) which was adjusted to two pHs (6.5 and 2.0) followed by

143 rinsing with LC/MS-grade water to remove salts and finally eluting with $12 \mathrm{~mL}$ LC/MS-grade

144 methanol. Initial sample volume was approximately $1 \mathrm{~L}$ for water column samples and between

$14540-60 \mathrm{~mL}$ for pore water samples. Samples were evaporated down to $\sim 300-400 \mu \mathrm{L}$ in a $\mathrm{N}_{2}$ dryer

146 and stored frozen at $-20^{\circ} \mathrm{C}$ until analysis. SPE and drying occurred in the dark, and samples were

147 protected from light. A liquid phase extraction was performed on the preconcentrated pore water

148 samples to remove any potentially interfering hydrophobic organic compounds and increase the

149 signal to noise ratio as described further in Supporting Information.

\section{Standards and LC/MS Instrument Settings}

151 A Thermo high-performance liquid chromatography/tandem triple quadrupole mass

152 spectrometer (LC/MS) fit with an electrospray ionization interface (ESI) was used for flavin

153 detection (Waltham, MA, USA). A previous method had been developed to measure RF, and

154 this method was adapted to measure the other flavin analytes. ${ }^{27-28}$ A Supelco Analytical

155 Discovery ${ }^{\circledR} \mathrm{HS} \mathrm{C}_{18}$ column ( $10 \mathrm{~cm}$ x $2.1 \mathrm{~mm}, 5 \mu \mathrm{m}$; Sigma-Aldrich, St. Louis, MO, USA) was

156 used with a gradient elution of mobile phase $\mathrm{A}-\mathrm{LC} / \mathrm{MS}$ grade water adjusted to $\mathrm{pH} 4.5$ with

$1570.5 \%$ acetic acid and mobile phase B - LC/MS grade methanol with $0.5 \%$ acetic acid. The flow 
rate was $230 \mu \mathrm{L} / \mathrm{min}$ with a beginning gradient of $93 \%$ water and $7 \% \mathrm{MeOH}$ changing to $100 \%$

organic phase by $7 \mathrm{~min}$ which was held for $2 \mathrm{~min}$ and returned to initial conditions by 14

160 minutes. Flavin standards were obtained from Fluka ${ }^{\circledR}$ Analytical (Honeywell International, Inc.,

161 Morris Plains, NJ, USA) for RF and Sigma-Aldrich (St. Louis, MO, USA) for FMN, LC, and LF

162 as well as the internal standard Riboflavin-(dioxopyrimidine- ${ }^{13} \mathrm{C}_{4},{ }^{15} \mathrm{~N}_{2}$ ) (heavy-RF). Standards

163 were stored protected from light at $-20^{\circ} \mathrm{C}$ except $\mathrm{RF}$ which was stored at $4^{\circ} \mathrm{C}$ as instructed by the

164 manufacturer. An instrumental response factor was calculated to establish a relationship

165 between the internal standard and each individual analyte (see Supporting Information). This

166 response factor was calculated daily to account for any variations in instrument sensitivity as

167 previously described. ${ }^{29}$

168 Flavin Quantification

169 Samples were thawed, $\mathrm{pH}$ adjusted to 6.5 with $0.01 \% \mathrm{NaOH}$, centrifuged for 3 minutes at $1705000 \mathrm{rpm}$, filtered with a 0.2- $\mu \mathrm{m}$ Minisart $®$ RC 4 filter (Sartorius, Göttingen, Germany) and

$171 \mathrm{MeOH}-$ rinsed $1 \mathrm{~mL}$ Norm-ject@ syringes (Air-Tite Products Co., Inc., Virginia Beach, VA, 172 USA), and the final sample mass was recorded. Samples were spiked with the internal standard $17350: 50 \mathrm{v} / \mathrm{v}$ and injected in triplicate into the LC/MS with a no-waste $50 \mu \mathrm{L}$ injection. Blanks of

174 Milli-Q water were run between each sample to prevent sample carryover. Daily internal

175 standard response factors and calibration curves were determined with curves generally

176 producing $\mathrm{R}^{2} \geq 0.98$ which bracketed concentrations of the expected environmental samples

177 ranges (see Supporting Information). The efficiency of the SPE was assessed using a procedural

178 spike and blank prepared using seawater previously passed through $\mathrm{C}_{18}$ resin and

179 preconcentrated alongside the samples; the procedural spike used the same seawater with the 180 addition of flavin standards. Spike percent recovery was calculated by subtracting the seawater 
181 blank from the spike signal. Recoveries ranged from 74-101\% for RF and 77-97\% for FMN (see

182 Table S3). Instrument blanks of LC/MS grade water were found to be below detection. 192 following standard methods.

\section{Geochemical Characterization of Marine Sediments}

Fe and Mn levels in sediments were measured on a Thermo Scientific ${ }^{\text {TM }}$ Element 2 тм High Resolution Inductively Coupled Plasma Mass Spectrometer (HR-ICP-MS; Waltham, MA, USA). Acidified samples were stored for at least 1 month prior to analysis, after which they were subsampled and diluted with $5 \%$ Optima-grade $\mathrm{HNO}_{3}{ }^{-}$to fit within the calibration curve. An external calibration curve and internal indium standard were used for quantification. A seawater standard reference material (NASS-6; National Research Council Canada Certified Reference Materials) ${ }^{30}$ was used to ensure instrument accuracy and correct for instrument drift. $\mathrm{SO}_{4}{ }^{2-}$ concentrations were measured on a Metrohm Ion Chromatograph (Herisau, Switzerland)

\section{Microbial Community Analysis}

\section{Cell counts, DNA extraction and 16S rRNA amplicon generation}

Microbial abundance in sediment samples was measured via cell counts using epifluorescence microscopy; further details are described in the Supporting Information. ${ }^{31}$ DNA was extracted from sediment samples in duplicate from 0.5-1.0 g subsamples of frozen sediment using the MP Biomedical FastDNA SPIN Kit for Soil (Santa Ana, CA). Duplicate extracted community DNA from the same sample was then combined for PCR analysis of the V4/5 region of the 16S rRNA gene using the protocol of Parada et al. ${ }^{32}$; further described in the Supporting Information.

Sequence pools were concentrated (Agencourt ${ }^{\circledR}$ Ampure ${ }^{\circledR}$ XP, $0.8 \mathrm{x}$ beads) and assessed for quantity (Invitrogen Qubit dsDNA HS Assay Kit) and quality (Agilent High Sensitivity DNA Kit Bioanalyzer Chip) before submitting for Illumina 2x300 MiSeq PE sequencing at UC-Davis (Set 
204 1) or 2x250 HiSeq PE sequencing at USC (Set 2). Extraction blanks, PCR negative controls, and 205 mock communities were sequenced and bioinformatically processed in parallel to assure quality 206 control of PCR and sequencing reactions. ${ }^{32}$ Raw Illumina data for each sample can be accessed 207 at the National Institute for Bioinformatics Short Read Archive under Accession \# SRP155917.

208 Bioinformatics analysis

209 Analysis of amplicons of the V4/5 region of the 16S rRNA gene, hereafter referred to as 210 iTags, was carried out in mothur v.1.35.1 following the method of Kozich et al. ${ }^{33-34}$ Paired reads 211 were combined into contigs and quality filtered to exclude sequences containing ambiguous base 212 calls or homopolymer runs longer than $8 \mathrm{bp}$. The merged contigs were then aligned with the

213 SILVA non-redundant 16S rRNA reference dataset (v.119). Aligned sequences were 'pre-

214 clustered' using 3-bp difference. ${ }^{35}$ Chimeric sequences were identified with the UCHIME

215 algorithm and removed from further processing and analysis. ${ }^{36}$ Sequences were then clustered 216 into different operational taxonomic units (OTUs) at 3\% or less dissimilarity using the average 217 neighbor method.

218 A final curated dataset containing 17,897 OTUs clustered from 605,012 iTags was used for 219 analysis of community composition and network analysis according to current best practice. ${ }^{37}$

220 Further details of the analysis pipeline are given in Supporting Information. Each library

221 contained an average of 55,001 $\pm 31,902$ sequences. Rarefaction curves for all samples

222 approached saturation (Figure S7). Diversity and richness indices (observed richness, Inverse

223 Simpson, Chao1, ACE) were calculated from the average (1000 iterations) of rarefying libraries

224 to the smallest library size (17,131 sequences). Patterns in microbial community structure were

225 examined based on the Bray-Curtis dissimilarity index. ${ }^{38}$ Rarefied data was used for calculating 
226 diversity and richness and Bray-Curtis based on recent analysis of best practice for calculating $\alpha$

227 and $\beta$-diversity metrics. ${ }^{39}$

$228 \quad$ Network Analysis

229 OTUs present at mean relative abundance $\geq 0.1 \%$ overall in the unrarefied dataset were

230 included in a local similarity analysis, ${ }^{40}$ generated in $\mathrm{R}$ version $3.3 .0^{41}$ using the rcor.test function

231 in the "ltm" package. ${ }^{42}$ Environmental variables (Fe, Mn, RF, FMN) were z-score transformed to

232 account for differences in units and to reduce the effect of outliers. ${ }^{43}$ False positives were tested

233 for using the $\mathrm{q}$ statistic with the R package qualue, ${ }^{44}$ and only correlations where $\mathrm{p}<0.001,{ }^{37} \mathrm{q}-$

234 statistic $<0.05$ and the Pearson's correlation was $>0.70$ were subsequently used for network

235 visualization in Cytoscape 3.5. ${ }^{45}$

\section{Results and Discussion}

\section{$237 \quad$ Flavin Concentrations}

238 Total dissolved flavin concentrations in SPOT-water column and pore waters ranged from

239 high pico- to low nano-molar concentrations with highest concentrations occurring in pore

240 waters (14-210 pM RF and 93-2070 pM FMN; Figure 1). The concentration of FMN showed a

241 strong positive correlation with RF in both the water column and pore waters $(r=0.91 ; p<0.005$;

242 Figure S6). Water column samples ranged from 14-40 pM for RF and 93-300 pM for FMN with

243 a 1.7- and 1.3-fold decrease, respectively, in concentration in the upper 700-m of the water

244 column. An elevated concentration gradient for both analytes was observed below the basin sill

245 (2.9- and 3.1-fold increase for RF and FMN respectively, see Table S5) indicating a likely

246 sediment source. Although known to rapidly photodegrade ${ }^{22}$ and exhibit strong surface water

247 diurnal variations ${ }^{46}$ concentrations were still detectable in the photic zone, likely indicating

248 recent cellular production. RF concentrations fell within the range of the only two previously 
249 reported LC/MS measurements ranging from $<0.7$ to $4.4 \mathrm{pM}$ in the Baja California Coast,

250 Mexico and 45 to $128 \mathrm{pM}$ in the Hood Canal, Washington, USA. ${ }^{27,47}$ The RF concentrations

251 also fall within the range reported from a number of studies from the 1980s-1990s which

252 recorded marine measurements based on fluorescence and found concentrations ranging from 0-

253100 pM. $^{23,48-50}$ Another study ${ }^{51}$ investigated vertical distributions of total flavins (reported only

254 as relative fluorescence) in the Caribbean and Black Sea and observed an increase in flavin

255 fluorescence with depth. The elevated fluorescence with depth was attributed to diffusion from

256 sediments and/or elevated production in sulfidic bottom waters similar to the increase in

257 concentration observed below the sill depth at SPOT.

258 The concentration of the degradation products, LC and LF, exhibited the highest

259 concentrations (137 pM LC and $25 \mathrm{pM} \mathrm{LF)} \mathrm{within} \mathrm{the} \mathrm{photic} \mathrm{zone} \mathrm{at} 10$ meters. Concentrations

260 dropped to 5-10 pM for LC and 2-7 pM for LF and remaining stable in the deeper water column

261 depths. The LC and LF water column concentrations measured in the San Pedro Basin agree

262 well with previous fluorescence analyses in the Mediterranean and Black Sea where

263 concentrations ranged from $0-90 \mathrm{pM}$ for LC and 0-55 $\mathrm{pM}$ for LF with the highest concentrations

264 occurring in the photic zone. ${ }^{51-52}$ Despite being degradation products of RF and FMN, select

265 studies have found that LC and LF may serve important roles in the microbial community as

266 quorum sensing molecules. 53 They have also been found to have strong photosensitization

267 properties $^{50}$ and thus could serve a role in breaking down larger, complex dissolved organic

268 material which is rapidly recycled in the photic zone. ${ }^{46,54}$ The extent of this effect in the surface

269 ocean microbial community has not been previously investigated and requires additional study.

270 Pore water concentrations of LC and LF are not reported because the chloroform extraction used

271 to reduce hydrophobic interferences in the samples inhibited LC and LF detection (Figure S4). 
272 However, because LC and LF are primarily formed via photodegradation, their concentrations

273 are expected to be minimal in pore waters of the deep basin.

274 RF and FMN pore water concentrations were significantly higher (approximately 5-7 times)

275 than bottom water (below the sill) concentrations measured at SPOT (Figure 1). The

276 concentration of both metabolites increased with sediment depth and also exhibited a local

277 maximum around 3-5 cm, most noticeably for FMN. The two separate cores showed similar

278 concentrations and coherence in profile trends, which implies that the spatial heterogeneity of

279 pore water flavin concentrations is low but not negligible, at least within the area of the ship drift

280 between multicore drops (likely meter-length distances). Porewater concentrations of RF and

281 FMN have not been previously reported in the literature, therefore these measurements represent

282 the first evidence that sedimentary environments contain these known electron-mediating

283 compounds. FMN was consistently higher than its precursor RF, which is intriguing as this

284 compound is thought to be less stable than RF because of the ribitol - phosphate bond, which is

285 susceptible to cleavage by extracellular phosphatase enzymes previously detected in SPOT

286 sediments. $^{55}$ FMN is also relatively more energetically expensive than RF for a cell, which must

287 use the protein riboflavin kinase and invest an ATP molecule to convert RF to FMN. ${ }^{3}$

288 Classic geochemical dissolved organic carbon pore water profiles predict that the abundance

289 of labile dissolved organic carbon (such as flavins) would dominate in shallow depths $(\sim 2 \mathrm{~cm})$

290 where the highest carbon turnover occurs and decrease with depth as more recalcitrant organic

291 carbon compounds increase in relative abundance. ${ }^{56}$ Examples include pore water profiles of

292 amino acids ${ }^{57}$ and extracellular DNA $^{58}$ which tend to covary with cell counts and display the

293 highest concentrations in the shallowest sediment depths. However, the concentration of

294 extracellular flavins at SPOT did not correlate with cellular biomass and displayed the lowest 
concentration in the shallowest sediment horizon where cellular abundance was the highest

296 (Figures 1 and S8). While cellular lysis due to viral infection and grazing likely contributes to a

297 portion of the extracellular flavin pool, active secretion of extracellular flavins by organisms

298 living deeper in the sediment could explain the observed flavin gradient and dominance of the

299 phosphorylated form, FMN.

300
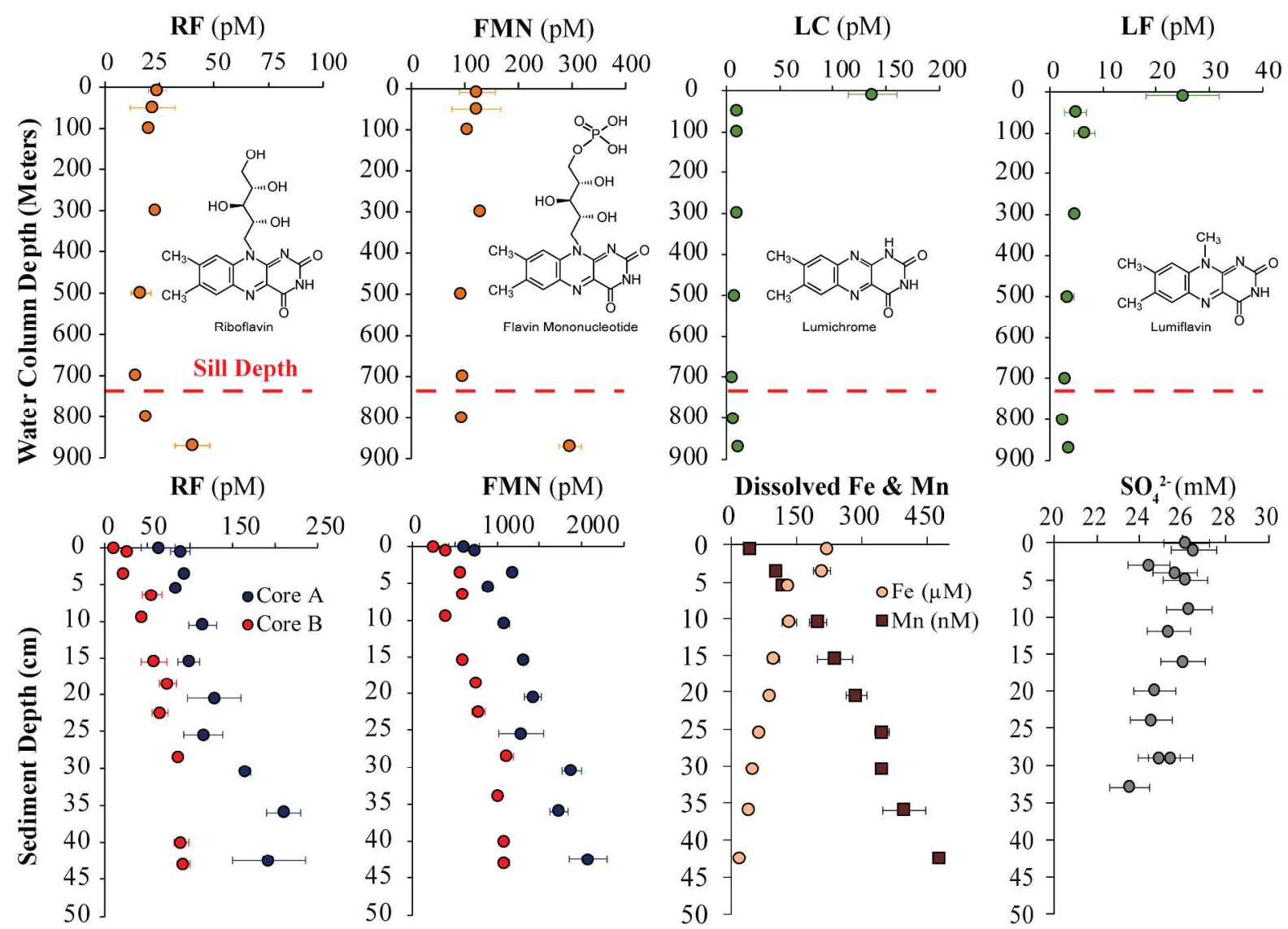

302 Figure 1. Flavin (RF - Riboflavin, FMN - Flavin Mononucleotide, LC - lumichrome, LF -

303 lumiflavin) concentrations (pM) in the water column and flavin and total dissolved Fe, Mn and

$304 \mathrm{SO}_{4}{ }^{2-}$ pore water concentrations. Error bars for RF, FMN, LC, and LF represent the standard

305 deviation of the triple injection of a single sample. Total dissolved Fe $(\mu \mathrm{M})$ and $\mathrm{Mn}(\mathrm{nM})$ were 
measured in the same core, and $\mathrm{SO}_{4}{ }^{2-}(\mathrm{mM})$ concentrations were measured in two ancillary cores

307 collected on the same day. Trace metal error bars represent the standard deviation of multiple

308 instrument injections and when not visible are smaller than the symbol. $\mathrm{SO}_{4}{ }^{2-}$ error bars

309 represent the $4 \%$ standard deviation measured on triplicate samples.

\section{$310 \quad$ Flavin Ratios}

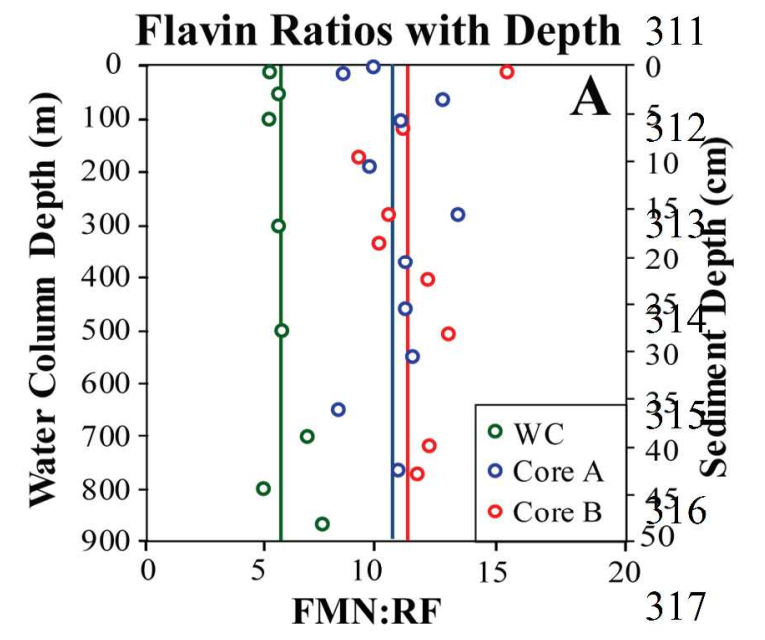

Figure 2. Environmental Flavin Ratios. Panel A shows flavin ratios (FMN:RF) with depth for the water column (WC) and pore water samples (Cores A and B). Panel B shows flavin ratios (FMN: RF) from this study (colored bars) as compared to results published by von Canstein et al., 2008 (gray bars). ${ }^{8}$

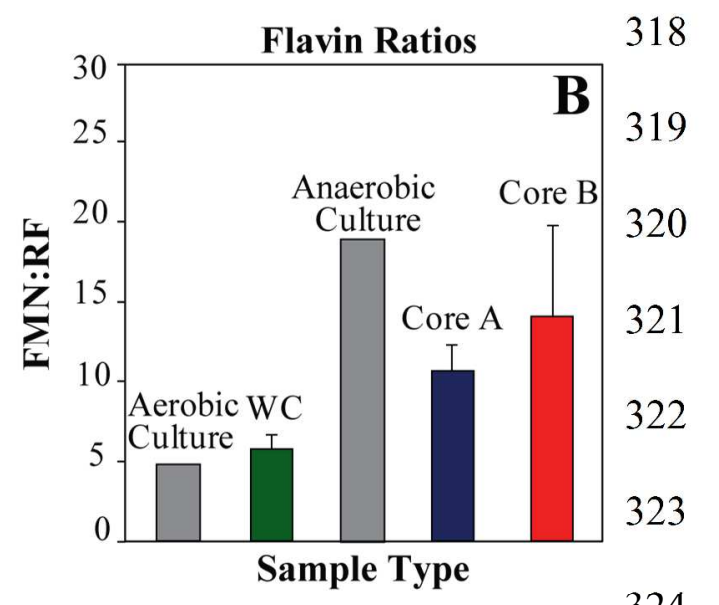

To compare the flavin analytes, molar ratios of FMN:RF were calculated. Flavin ratios did not vary substantially within each environment, but varied between water column and pore waters (Figure 2). Flavin ratios were $5.8 \pm 0.8$ in the water column, while pore water ratios were roughly twice as high with ratios of $10.6 \pm 1.6$ for Core A and $11.6 \pm 1.8$ for

325 Core B (excluding two outliers of 24 and 27 at 0 and $3.5 \mathrm{~cm}$ ). The difference between the

326 FMN:RF molar ratios observed in the water column versus pore water agrees well with previous

327 work which measured flavin concentrations in cultures of Shewanella in the presence and

328 absence of oxygen. ${ }^{8}$ Previous studies have found SPOT sediments to be anoxic within $\mathrm{mm}^{25}$ 
329 from the sea water-sediment interface whereas the water column was oxic to suboxic

330 throughout. ${ }^{59}$ We postulate that the near doubling of the FMN:RF ratio in the pore waters to

331 values $>10$ may be an indicator of cellular release of FMN under anoxic conditions. The work

332 of von Canstein and collaborators measured both intra- and extracellular concentrations of flavin

333 in various species of Shewanella. ${ }^{8}$ They found that extracellular FMN:RF ratios were $\sim 4.8$ under

334 aerobic conditions and rose to $\sim 19$ under anoxic culture conditions. ${ }^{8}$ The cause for the difference

335 in secretion rates of the two flavins under anoxic versus oxic conditions in Shewanella is

336 unknown but may be due to the binding mechanisms of the flavin to the OMC which requires an

337 oxygen-sensitive disulfide bond. ${ }^{60}$ FMN, the preferred cofactor for the OMC in Shewanella,

338 may be preferentially secreted under anoxic conditions when it is able to bind to the cytochrome.

$339 \mathrm{Fe}, \mathrm{Mn}$, and $\mathrm{SO}_{4}{ }^{2-}$ Pore Water Profiles

340 Total dissolved Fe concentrations (Figure 1) ranged from $\sim 200 \mu \mathrm{M}$ in the shallowest pore

341 waters, at $0.5 \mathrm{~cm}$, down to $18 \mu \mathrm{M}$ in the deepest measured pore waters $(40 \mathrm{~cm})$, while total

342 dissolved Mn concentrations were $\sim 40 \mathrm{nM}$ at $0.5 \mathrm{~cm}$ and increased to $480 \mathrm{nM}$ at $40 \mathrm{~cm}$. We did

343 not measure the concentration of $\mathrm{Fe}^{2+}$ and $\mathrm{Mn}^{2+}$ but assumed that most of the total dissolved pore

344 water is reduced based on the anoxic conditions of the sediments. However, we could not rule

345 out the presence of colloidal and/or organic complexed $\mathrm{Fe}^{3+}, \mathrm{Mn}^{3+}$, or $\mathrm{Mn}^{4+}$ in the pore waters

346 that could influence our interpretation. $\mathrm{SO}_{4}{ }^{2-}$ was measured on two nearby cores and displayed a

347 decrease in concentration from $26 \mathrm{mM}$ at $0.5 \mathrm{~cm}$ to $24 \mathrm{mM}$ at $35 \mathrm{~cm}$ indicating active $\mathrm{SO}_{4}{ }^{2-}$

348 reduction within SPOT sediments (Figure 1).

349 The pore water profiles of $\mathrm{Fe}, \mathrm{Mn}$, and $\mathrm{SO}_{4}{ }^{2-}$ are indicative of a zone of active carbon

350 turnover and utilization of terminal electron acceptors. This carbon-rich coastal basin appears to

351 be largely dominated by $\mathrm{SO}_{4}{ }^{2-}$ reduction. The typical maxima of dissolved $\mathrm{Fe}$ and $\mathrm{Mn}$, which 
352 indicate zones of oxide reduction, were not evident at our $\mathrm{cm}$-scale sampling. However, the 353 majority of Fe and Mn reduction likely occurs in the top few $\mathrm{cm} .{ }^{61}$ The loss of dissolved Fe with 354 sediment depth could be caused by a coupling with $\mathrm{SO}_{4}{ }^{2-}$ reduction to $\mathrm{H}_{2} \mathrm{~S}$ and formation of $\mathrm{FeS}_{2}$ 355 as has been observed in adjacent Santa Monica Basin. ${ }^{61}$ The total dissolved Mn profile was 356 lower than nearby basins which typically reach $\mu \mathrm{M}$ concentrations ${ }^{62}$ but agreed with previous 357 measurements made in the Santa Monica Basin. ${ }^{63}$

358 Flavins are known to enhance both $\mathrm{Fe}$ and Mn reduction at concentrations similar to those 359 measured here (e.g., $2 \mathrm{nM}){ }^{64}$ A positive correlation was observed between flavins and total 360 dissolved $\mathrm{Mn}(\mathrm{r}=0.91, \mathrm{p}=0.00022$ for FMN; $\mathrm{r}=0.87, \mathrm{p}=0.0011$ for RF, Figure S5) which 361 supports the hypothesis that cells may utilize flavins in order to reduce insoluble Mn oxides in 362 surface sediments. Recent work by Michelson et al., found that flavins are used as cofactors for 363 the nanowires of Geobacter sulfurreducens to reduce the Mn-bearing mineral birnessite present 364 in pore spaces too small for the cell to access. ${ }^{65}$ While Geobacter taxa were not identified in our 365 16s rRNA analysis, the dissolved flavins may serve a similar role for other sediment organisms. 366 Unlike $\mathrm{Fe}$, reduced $\mathrm{Mn}$ will not react with $\mathrm{H}_{2} \mathrm{~S}$ under typical marine conditions and therefore 367 there is no sink for total dissolved Mn at depth in the sediments, thus allowing the dissolved Mn 368 concentration to increase with depth as flavins also accumulate, resulting in a positive correlation 369 with dissolved flavins.

370 A negative correlation was observed between total dissolved Fe and extracellular flavins ( $\mathrm{r}=-$ $3710.85, \mathrm{p}=0.0019$ for $\mathrm{FMN} ; \mathrm{r}=-0.79, \mathrm{p}=0.0063$ for $\mathrm{RF}$ ). This negative correlation could occur 372 because of the presence of a the $\mathrm{FeS}_{2}$ sink at depth. A similar sink is not known to exist for 373 flavins, thus allowing flavin concentration to remain relatively high as dissolved Fe is removed. 374 However, to have an increase of flavins with depth, a deeper source is required, possibly linked 
375 to $\mathrm{SO}_{4}{ }^{2-}$ reduction or another unidentified source. Flavins are a required cofactor in $\mathrm{SO}_{4}{ }^{2-}$

376 reduction to transfer electrons from adenosine 5'-phosphosulate to sulfite ${ }^{2}$ and flavin redox

377 potential makes them well suited to perform electron transfer for many of the specific reactions

378 involved in $\mathrm{SO}_{4}{ }^{2-}$ reduction (average overall reaction $\mathrm{E}^{\mathrm{o}}=-0.218 \mathrm{~V}$ ). ${ }^{66}$ In addition, flavins are

379 known to reduce other metals and can be used in organohalide respiration ${ }^{67}$ commonly

380 performed by select lineages identified in our network analysis (discussed further below),

381 leaving the possibilities for the deeper flavin source largely unconstrained. Studies have also

382 shown that negative correlations can exist between flavins and $\mathrm{Fe}$ because of overproduction and

383 release of flavins under Fe limitation in certain species. ${ }^{68}$ While we cannot rule out the

384 possibility that Fe limitation may exist in some microenvironments, it is unlikely to be limiting in

385 pore waters with $\mu \mathrm{M}$ concentrations of dissolved Fe. Therefore, we attribute the local surface

386 maxima of flavins (around $\sim 5 \mathrm{~cm}$ ) to production by $\mathrm{Fe}$ and $\mathrm{Mn}$ reducers while the increase of

387 flavins with depth is likely due to a yet unknown flavin source possibly linked to $\mathrm{SO}_{4}{ }^{2-}$ reduction

388 or organohalide respiration.

389 These pore water data provide evidence for putative coupling between flavin distribution

390 and terminal electron utilization; however, we are cautious to assign a mechanistic connection to

391 a correlation which may instead be primarily controlled by sediment depth (Figure S5). In

392 addition, our sampling technique is unable to fully preserve the microenvironments which exist

393 in the pore spaces of the sediment. The signals that we see at the $\mathrm{cm}$ level are unlikely to be

394 representative of the processes occurring at the cellular level. Furthermore, our sampling

395 techniques only allow us to measure the dissolved fraction of flavins present in the system.

396 Flavins, and in particular FMN, are known to be particle reactive and adsorb to metal oxides; ${ }^{69}$

397 therefore, we likely are only observing a small fraction of the total available pool of flavins in the 
sediment. Therefore, we expect that the effective concentration of flavins surrounding a cell and/or metal oxide are likely to be higher than the concentrations that we present here.

\section{Microbial Community Analysis}

Microbial cells in surface sediments $\left(0-1 \mathrm{~cm} ; \sim 5.5 \times 10^{7}\right.$ cells $\left./ \mathrm{cm}^{3}\right)$ were an order of magnitude

402 more abundant than at $30 \mathrm{~cm}\left(1.8 \times 10^{6} \mathrm{cells} / \mathrm{cm}^{3}\right)($ Table $\mathrm{S} 7$ and Figure S8). The reduction in cell

403 density with depth leveled off around $10 \mathrm{~cm}$ and slowly decreased down to the deepest sample

404 analyzed at $30 \mathrm{~cm}$ depth. The relative abundance of the microbial community taxa in SPOT

405 sediments showed a well-stratified composition that transitioned gradually with depth (Figure

406 S8). Five of the top ten most abundant Operational Taxonomic Units (OTUs) detected belong to

407 the Desulfobacteraceae and Desulfarculaceae families of Deltaproteobacteria (Table S8) that are

408 known to exclusively perform $\mathrm{SO}_{4}{ }^{2-}$ reduction, which corroborates the geochemical profile

409 discussed earlier (Figure 1). The surface sediment $(0-5 \mathrm{~cm})$ was dominated by

410 Deltaproteobacteria (22-32\%; predominately Desulfobacterales and unclassified

411 Deltaproteobacteria) and Gammaproteobacteria (5-19\%; predominately Xanthomondales,

412 Chromatiales, and unclassified Gammaproteobacteria). Around $10 \mathrm{~cm}$, the relative abundance of

413 Chloroflexi (16-32\% over 10-39 cm, predominantly Anaerolineae and Dehalococcoidia)

414 increased while Gammaproteobacteria and Bacteroidetes decreased. Archaea also increased in

415 abundance over 10-39 $\mathrm{cm}$ (7-23\%) followed by increasing relative abundance of Atribacteria,

416 Omnitrophica, and Arminicenantes (previously known as Candidate Divisions JS1, OP3, and

417 OP8, respectively). Deltaproteobacteria remained abundant but decreased in relative abundance

418 between 20 and $39 \mathrm{~cm}$.

419 A network analysis ${ }^{40,70}$ was conducted to determine the OTUs that were correlated with 420 FMN, RF, Mn and/or Fe concentrations (Figure 3). Overall, 19 OTUs were positively correlated 
421 to FMN, RF and Mn and negatively correlated to Fe. An additional 25 OTUs showed positive

422 interactions with one or more of FMN, RF and Mn. OTUs classified as Chloroflexi comprise $42343 \%$ of the OTUs positively correlated with flavins. In particular, OTUs classified within the

424 class Dehalococcoidia (16 OTUs) were positively correlated with FMN and/or RF. This

425 correlation persists at the class and order level as well (Table S8). Dehalococcoidia, named

426 based on their ability to respire halogenated compounds, can employ a flavin-based halogenase, ${ }^{67}$

427 but flavin secretion has not been previously reported, and the exact metabolic pathway is still 428 unresolved in some of the clades found in this study (e.g., vadinBA26 and GIF9). A positive 429 interaction between FMN and RF with five OTUs classified as the MSBL9 clade of

430 Planctomycetes was also observed. This group of bacteria are known to perform fermentation ${ }^{71}$

431 and are commonly observed in sedimentary environments. ${ }^{72-73}$ Additionally, multiple OTUs

432 classified as Thermoplasmatales (phylum Euryarchaeota) and Thermoprotei (phylum

433 Crenarchaeota), both of which are known to be flavin prototrophs, ${ }^{74}$ and Sva0485 (class

434 Deltaproteobacteria) were positively correlated with FMN and/or RF. Only eight OTUs

435 displayed negative interactions with FMN and/or RF, half of which were classified as

436 Deltaproteobacteria.

437 Correlations between relative community abundance and dissolved environmental flavin 438 concentrations can be used to form future hypotheses but cannot be used to infer metabolic

439 function. Our 16S rRNA analysis revealed a number of taxa which may have a role to play in 440 flavin secretion and/or utilization but we were unable to identify a known cultured isolate or a 441 single environmental taxa most likely to be tied to the flavin profile. In addition, while we make 442 the hypothesis that flavins are actively secreted by the microbial community, we are unable to 443 rule out the possibility that flavins may simply be present because of cell lysis via viral activity 
444 and/or grazing. Regardless of their source, the microbial community may still access the

445 extracellular flavin pool for use as flavocoenzymes and electron transfer and therefore making 446 them valuable redox active constituents of the dissolved organic pool.

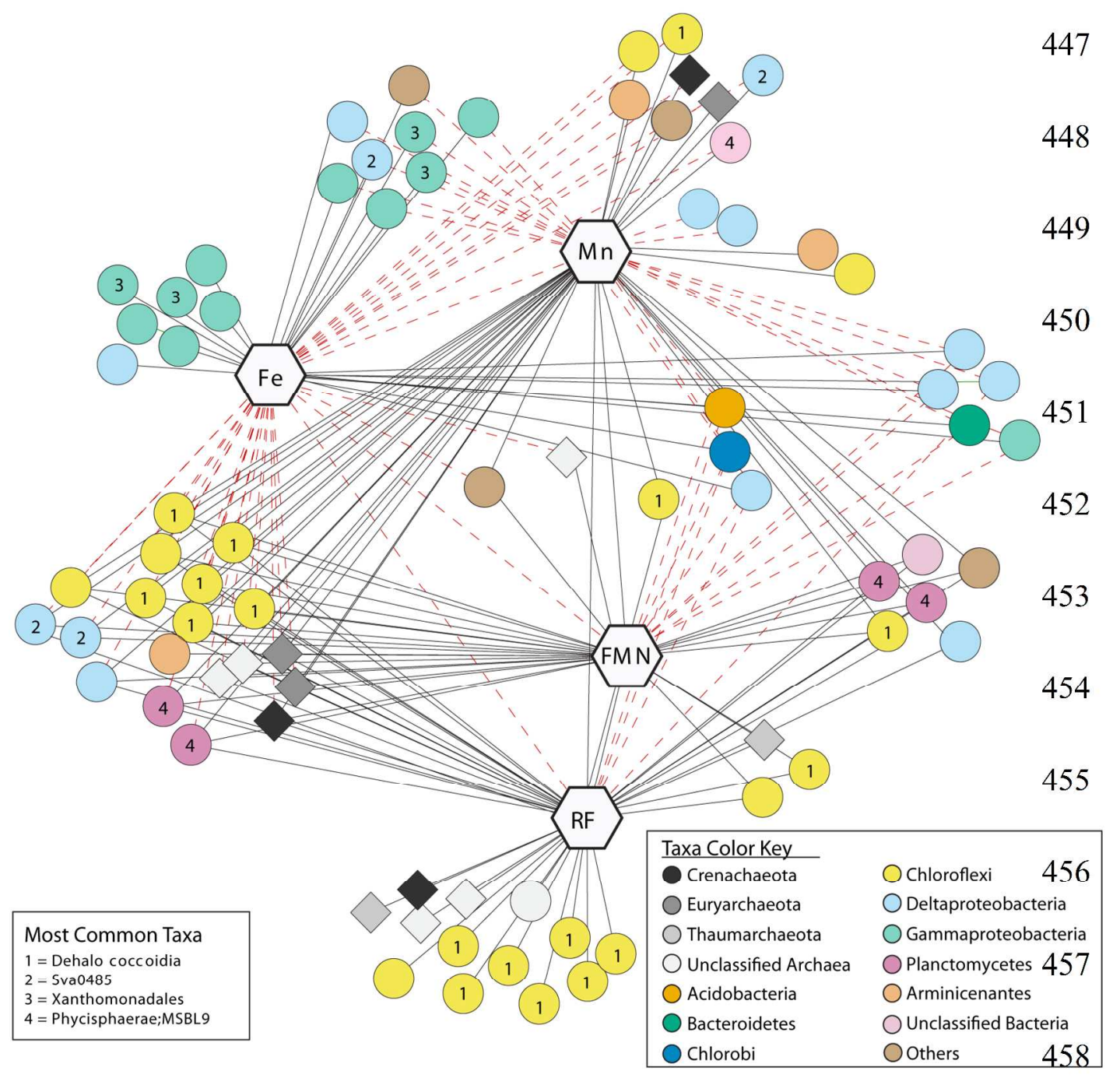

459 Figure 3. Network analysis of 16S rRNA OTUs with correlations to at least one of riboflavin

460 (RF), flavin mononucleotide (FMN), Mn and/or Fe. Black lines indicate positive correlations;

461 dashed red lines indicate negative correlations. Phylogenetic classification of OTUs is presented

462 in Fig. S9 but left blank here for clarity. The four most common taxa are indicated by numbers.

463 Circles represent bacterial OTUs and diamonds represent archaeal OTUs.

$464 \quad$ Implications 
465 Our study demonstrates that extracellular flavins are available within the natural environment,

466 exhibit concentration gradients across cm-scale redox boundaries, and are positively correlated to

467 specific bacterial and archaeal OTUs. OTUs classified as Dehalococcoidia were the most

468 common lineage correlated to flavins, a correlation that existed at the class level as well. Further

469 understanding of the phylogenetic distribution of OTUs and traits associated with flavins may

470 allow future assessment of relationships between flavins and microbial taxa at higher taxonomic

471 levels. The low midpoint redox potential of flavins make them ideal reductants for the majority

472 of redox active metals, as well as nitrogen cycling, ${ }^{75}$ and portions of the sulfur cycle. Many

473 studies have identified their ability to reduce hazardous metals such as U (VI), ${ }^{11}$ and $\mathrm{Cr}(\mathrm{VI}){ }^{76-77}$

474 Studying their distribution, sources, and sinks in the natural environment will aide our

475 understanding of their role in natural microbial communities, help identify potential applications

476 for use in remediation of contaminated sites, and move us further towards understanding the

477 ubiquity and main drivers of natural flavin cycling.

\section{Author Information}

479 Corresponding Author

480 dmonteverde@caltech.edu

$481 \quad$ Notes

482 The authors declare no competing financial interest.

\section{Acknowledgements}

484 We thank Nick Rollins, Elias Karkabi, and Lynda Cutter (University of Southern California)

485 for help in sample collection and analysis, Willie Haskell and Doug Hammond (USC) for cruise 
486 support, Cole Hastings for help with cell counts, and Annette Rowe (USC) for flavin discussions. 487 Support for this work was provided by National Science Foundation Grants OCE 1435666 and 488 1260692, startup funds from Texas A\&M University to JBS, and Caltech Division of Geological 489 and Planetary Sciences Geobiology Postdoc salary for DRM.

490 Supporting Information

491 Includes a word document with 9 figures of flavin structures, sample site, calibration curves, 492 chloroform extraction recovery, statistical correlations, flavin Pearson correlations, rarefaction 493 curves, 16S rRNA microbial community profile, network diagram with OTUs, 8 tables of 494 LC/MS flavin optimization conditions, LC/MS instrument parameters, analyte detection 495 conditions, dissolved Fe and Mn concentrations, flavin concentrations, iTag OTUs, and 496 correlations between lineages and flavins. Excel file with shared file of OTUs used in this 497 study. Data presented is in reads per sample. This information is available free of charge via the 498 Internet at http://pubs.acs.org. 


\section{References}

1. Leys, D.; Scrutton, N. S., Sweating the assets of flavin cofactors: new insight of chemical versatility from knowledge of structure and mechanism. Current Opin. Struct. Biol 2016, 41, $19-26$.

2. Monteverde, D. R.; Gómez-Consarnau, L.; Suffridge, C.; Sañudo-Wilhelmy, S. A., Life's utilization of B vitamins on early Earth. Geobiology 2016, 15, 1-16.

3. Macheroux, P.; Kappes, B.; Ealick, S. E., Flavogenomics - a genomic and structural view of flavin-dependent proteins. Febs J. 2011, 278 (15), 2625-2634.

4. Pallotta, M. L., Evidence for the presence of a FAD pyrophosphatase and a FMN phosphohydrolase in yeast mitochondria: a possible role in flavin homeostasis. Yeast 2011, $28(10), 693-705$.

5. Rajamani, S.; Bauer, W. D.; Robinson, J. B.; Farrow, J. M., III; Pesci, E. C.; Teplitski, M.; Gao, M.; Sayre, R. T.; Phillips, D. A., The Vitamin Riboflavin and Its Derivative Lumichrome Activate the LasR Bacterial Quorum-Sensing Receptor. Mol. Plant-Microbe Interact. 2008, 21 (9), 1184-1192.

6. Buckel, W.; Thauer, R. K., Energy conservation via electron bifurcating ferredoxin reduction and proton/Na+ translocating ferredoxin oxidation. Biochim. Biophys. Acta, Bioenerg. 2013, 1827 (2), 94-113.

7. Marsili, E.; Baron, D. B.; Shikhare, I. D.; Coursolle, D.; Gralnick, J. A.; Bond, D. R., Shewanella Secretes flavins that mediate extracellular electron transfer. Proc. Natl. Acad. Sci. U. S. A. 2008, 105 (10), 3968-3973.

8. von Canstein, H.; Ogawa, J.; Shimizu, S.; Lloyd, J. R., Secretion of flavins by Shewanella species and their role in extracellular electron transfer. Appl. Environ. Microbiol. 2008, 74 (3), 615-623. 
523 9. Okamoto, A.; Saito, K.; Inoue, K.; Nealson, K. H.; Hashimoto, K.; Nakamura, R., Uptake of 524 self-secreted flavins as bound cofactors for extracellular electron transfer in Geobacter $525 \quad$ species. Energy Environ. Sci. 2014, 7 (4), 1357-1361.

10. Sober, H. A., CRC Handbook of Biochemistry: Selected data for molecular biology. 2nd ed.;

527 The Chemical Rubber Company: Cleveland, Ohio, 1973.

528 11. Suzuki, Y.; Kitatsuji, Y.; Ohnuki, T.; Tsujimura, S., Flavin mononucleotide mediated 529 electron pathway for microbial U (VI) reduction. Phys. Chem. Chem. Phys. 2010, 12 (34), $530 \quad 10081-10087$.

531 12. Min, D.; Cheng, L.; Zhang, F.; Huang, X.-N.; Li, D.-B.; Liu, D.-F.; Lau, T.-C.; Mu, Y.; Yu, 532 H.-Q., Enhancing Extracellular Electron Transfer of Shewanella oneidensis MR-1 through 533 Coupling Improved Flavin Synthesis and Metal-Reducing Conduit for Pollutant Degradation. 534 Environ. Sci. Technol. 2017, 51 (9), 5082-5089.

535 13. Kotloski, N. J.; Gralnick, J. A., Flavin electron shuttles dominate extracellular electron 536 transfer by Shewanella oneidensis. mBio 2013, 4 (1), e00553-12.

537 14. Xu, S.; Jangir, Y.; El-Naggar, M. Y., Disentangling the roles of free and cytochrome-bound 538 flavins in extracellular electron transport from Shewanella oneidensis MR-1. Electrochim. $539 \quad$ Acta 2016, 198, 49-55.

540 15. Rowe, A. R.; Chellamuthu, P.; Lam, B.; Okamoto, A.; Nealson, K. H., Marine sediments 541 microbes capable of electrode oxidation as a surrogate for lithotrophic insoluble substrate 542 metabolism. Front. Microbiol. 2015, 5, 1-14.

543 16. Light, S. H.; Su, L.; Rivera-Lugo, R.; Cornejo, J. A.; Louie, A.; Iavarone, A. T.; Ajo-

544 Franklin, C. M.; Portnoy, D. A., A flavin-based extracellular electron transfer mechanism in 545 diverse Gram-positive bacteria. Nature 2018, 1.

546 17. Bacher, A.; Eberhardt, S.; Fischer, M.; Kis, K.; Richter, G., Biosynthesis of vitamin B2 547 (riboflavin). Annu. Rev. Nutr. 2000, 20 (1), 153-167. 
18. Wu, S.; Xiao, Y.; Wang, L.; Zheng, Y.; Chang, K.; Zheng, Z.; Yang, Z.; Varcoe, J. R.; Zhao, F., Extracellular electron transfer mediated by flavins in gram-positive Bacillus sp. WS-XY1 and Yeast Pichia stipitis. Electrochim. Acta 2014, 146, 564-567.

19. Mehta-Kolte, M. G.; Bond, D. R., Geothrix fermentans secretes two different redox-active compounds to utilize electron acceptors across a wide range of redox potentials. Appl. Environ. Microbiol. 2012, 78 (19), 6987-6995.

20. Welkie, G. W., Taxonomic distribution of dicotyledonous species capable of root excretion of riboflavin under iron deficiency. J. Plant Nutr. 2000, 23 (11-12), 1819-1831.

21. Borch, T.; Kretzschmar, R.; Kappler, A.; Cappellen, P. V.; Ginder-Vogel, M.; Voegelin, A.; Campbell, K., Biogeochemical redox processes and their impact on contaminant dynamics. Environ. Sci. Technol. 2009, 44 (1), 15-23.

22. Holzer, W.; Shirdel, J.; Zirak, P.; Penzkofer, A.; Hegemann, P.; Deutzmann, R.; Hochmuth,

560 E., Photo-induced degradation of some flavins in aqueous solution. Chem. Phys. 2005, 308 (1), 69-78.

23. Vastano, S. E.; Milne, P. J.; Stahovec, W. L.; Mopper, K., Determination of picomolar levels of flavins in natural waters by solid-phase ion-pair extraction and liquid chromatography. Anal. Chim. Acta 1987, 201, 127-133.

24. Fuhrman, J. A.; Cram, J. A.; Needham, D. M., Marine microbial community dynamics and

26. Barnett, P. R. O.; Watson, J.; Connelly, D., A multiple corer for taking virtually undisturbed

25. Berelson, W. M.; Hammond, D. E.; Johnson, K. S., Benthic fluxes and the cylcing of biogenic silica and carbon in two southern California borderland basins. Geochim. samples from shelf, bathyl and abyssal sediments. Oceanol. Acta 1984, 7 (4), 399-408.

573 Webb, E. A.; Prokopenko, M. G.; Berelson, W. M.; Karl, D. M., Multiple B-vitamin 
574

575

576

577

578

579

580

depletion in large areas of the coastal ocean. Proc. Natl. Acad. Sci. U. S. A. 2012, 109 (35), 14041-14045.

28. Monteverde, D. R. B vitamin distribution in modern marine sediments and their utilization in major biogeochemical cycles since early Earth. Ph.D. Dissertation, University of Southern California, Los Angeles, CA, 2016.

29. Suffridge, C.; Cutter, L.; Sanudo-Wilhelmy, S., A new analytical method for direct measurement of particulate and dissolved B-vitamins and their congeners in seawater. Front. Mar. Sci. 2017, 4 (11), 1-11.

30. Brophy, C.; Clancy, V.; Willie, S.; Yang, L., NASS-6: Seawater reference material for trace metals. 1 ed.; National Research Council Canada: 2012.

31. Kallmeyer, J.; Smith, D. C.; Spivack, A. J.; D'Hondt, S., New cell extraction procedure applied to deep subsurface sediments. Limnol. Oceanogr.: Methods 2008, 6 (6), 236-245.

32. Parada, A. E.; Needham, D. M.; Fuhrman, J. A., Every base matters: assessing small subunit rRNA primers for marine microbiomes with mock communities, time series and global field samples. Environ. Microbiol. 2015, 18 (5), 1403-14.

33. Kozich, J. J.; Westcott, S. L.; Baxter, N. T.; Highlander, S. K.; Schloss, P. D., Development of a dual-index sequencing strategy and curation pipeline for analyzing amplicon sequence data on the MiSeq Illumina sequencing platform. Appl. Environ. Microbiol. 2013, 79 (17), 5112-5120.

34. Schloss, P. D.; Westcott, S. L.; Ryabin, T.; Hall, J. R.; Hartmann, M.; Hollister, E. B.; Lesniewski, R. A.; Oakley, B. B.; Parks, D. H.; Robinson, C. J., Introducing mothur: opensource, platform-independent, community-supported software for describing and comparing microbial communities. Appl. Environ. Microbiol. 2009, 75 (23), 7537-7541.

35. Huse, S. M.; Welch, D. M.; Morrison, H. G.; Sogin, M. L., Ironing out the wrinkles in the rare biosphere through improved OTU clustering. Environ. Microbiol. 2010, 12 (7), 18891898. 
36. Edgar, R. C.; Haas, B. J.; Clemente, J. C.; Quince, C.; Knight, R., UCHIME improves sensitivity and speed of chimera detection. Bioinformatics 2011, 27 (16), 2194-2200.

37. Weiss, S.; Van Treuren, W.; Lozupone, C.; Faust, K.; Friedman, J.; Deng, Y.; Xia, L. C.; Xu, Z. Z.; Ursell, L.; Alm, E. J., Correlation detection strategies in microbial data sets vary widely in sensitivity and precision. ISME J. 2016, 10 (7), 1669-1681.

38. Bray, J. R.; Curtis, J. T., An ordination of the upland forest communities of southern Wisconsin. Ecol. Monogr. 1957, 27 (4), 325-349.

39. Weiss, S.; Xu, Z. Z.; Peddada, S.; Amir, A.; Bittinger, K.; Gonzalez, A.; Lozupone, C.; Zaneveld, J. R.; Vázquez-Baeza, Y.; Birmingham, A., Normalization and microbial differential abundance strategies depend upon data characteristics. Microbiome 2017, 5 (1), $1-18$.

40. Ruan, Q.; Dutta, D.; Schwalbach, M. S.; Steele, J. A.; Fuhrman, J. A.; Sun, F., Local

41. RCoreTeam R: A language and environment for statistical computing, Vienna, Austria, 2013.

42. Rizopoulos, D., ltm: An R package for latent variable modeling and item response theory analyses. Journal of statistical software 2006, 17 (5), 1-25.

43. Lima-Mendez, G.; Faust, K.; Henry, N.; Decelle, J.; Colin, S.; Carcillo, F.; Chaffron, S.; Ignacio-Espinosa, J. C.; Roux, S.; Vincent, F., Determinants of community structure in the global plankton interactome. Science 2015, 348 (6237), 12620731-12620739.

44. Dabney, A.; Storey, J. D.; Warnes, G., qvalue: Q-value estimation for false discovery rate control. $R$ package version 2010, 1 (0).

45. Shannon, P.; Markiel, A.; Ozier, O.; Baliga, N. S.; Wang, J. T.; Ramage, D.; Amin, N.; Schwikowski, B.; Ideker, T., Cytoscape: a software environment for integrated models of biomolecular interaction networks. Genome research 2003, 13 (11), 2498-2504. 
626 46. Remucal, C. K.; McNeill, K., Photosensitized amino acid degradation in the presence of 627 riboflavin and its derivatives. Environ. Sci. Technol. 2011, 45 (12), 5230-5237.

628 47. Heal, K. R.; Carlson, L. T.; Devol, A. H.; Armbrust, E. V.; Moffett, J. W.; Stahl, D. A.; Ingalls, A. E., Determination of four forms of vitamin $\mathrm{B}_{12}$ and other B vitamins in seawater by liquid chromatography/tandem mass spectrometry. Rapid Commun. Mass Spectrom. 2014, 28 (22), 2398-404.

48. Dunlap, W. C.; Susic, M., Determination of pteridines and flavins in seawater by reversephase, high-performance liquid chromatography with fluorometric detection. Mar. Chem. 1985, $17(3), 185-198$.

49. Coble, P. G.; Gagosian, R. B., The nature and distribution of fluorescent dissolved organic matter in the Black Sea and the Cariaco Trench. In Black Sea Ocean., Springer: 1991; pp 361-378.

50. Mopper, K.; Zika, R. G., Natural photosensitizers in sea water: riboflavin and its breakdown products. In Photochemistry of Environmental Aquatic Systems, Zika, R. G.; Cooper, W. J., Eds. ACS Publications: 1987; Vol. 327, pp 174-190.

51. Coble, P. G.; Gagosian, R. B.; Codispoti, L.; Friederich, G. E.; Christensen, J. P., Vertical distribution of dissolved and particulate fluorescence in the Black Sea. Deep-Sea Res. 1991, 38, S985-S1001.

52. Momzikoff, A.; Dallot, S.; Gondry, G., Distribution of seawater fluorescence and dissolved flavins in the Almeria-Oran front (Alboran Sea, western Mediterranean Sea). J. Mar. Syst. 1994, 5 (3-5), 361-376.

53. Phillips, D. A.; Joseph, C. M.; Yang, G. P.; Martinez-Romero, E.; Sanborn, J. R.; Volpin, H., Identification of lumichrome as a Sinorhizobium enhancer of alfalfa root respiration and shoot growth. Proc. Natl. Acad. Sci. U. S. A. 1999, 96 (22), 12275-12280.

54. Mopper, K., Organic chemical dynamics of the mixed layer: measurement of dissolved hydrophilic organics at sea. In Dyn. Proc. Chem. Upper Ocean, Springer: 1986; pp 137-157. 
652 55. Hewson, I.; Jacobson-Meyers, M. E.; Fuhrman, J. A., Diversity and biogeography of

653 bacterial assemblages in surface sediments across the San Pedro Basin, Southern California

654 Borderlands. Environ. Microbiol. 2007, 9 (4), 923-933.

655 56. Komada, T.; Burdige, D. J.; Crispo, S. M.; Druffel, E. R. M.; Griffin, S.; Johnson, L.; Le, D.,

656 Dissolved organic carbon dynamics in anaerobic sediments of the Santa Monica Basin.

657 Geochim. Cosmochim. Acta 2013, 110, 253-273.

658 57. Burdige, D. J.; Martens, C. S., Biogeochemical cycling in an organic-rich coastal marine

659 basin: 10. The role of amino-acids in the sedimentary carbon and nitrogen cycling. Geochim.

$660 \quad$ Cosmochim. Acta 1988, 52 (6), 1571-1584.

661 58. Vuillemin, A.; Horn, F.; Alawi, M.; Henny, C.; Wagner, D.; Crowe, S. A.; Kallmeyer, J.,

662 Preservation and Significance of Extracellular DNA in Ferruginous Sediments from Lake

663 Towuti, Indonesia. Front. Microbiol. 2017, 8, 1-15.

664 59. John, S. G.; Mendez, J.; Moffett, J.; Adkins, J., The flux of iron and iron isotopes from San

665 Pedro Basin sediments. Geochim. Cosmochim. Acta 2012, 93, 14-29.

666 60. Edwards, M. J.; White, G. F.; Norman, M.; Tome-Fernandez, A.; Ainsworth, E.; Shi, L.;

667 Fredrickson, J. K.; Zachara, J. M.; Butt, J. N.; Richardson, D. J.; Clarke, T. A., Redox Linked

668 Flavin Sites in Extracellular Decaheme Proteins Involved in Microbe-Mineral Electron

669 Transfer. Sci. Rep. 2015, 5, 1-11.

670 61. Leslie, B. W.; Hammond, D. E.; Berelson, W. M.; Lund, S. P., Diagenesis in anoxic

671 sediments from the California Continental Borderland and its influence on iron, sulfur, and

672 magnetite behavior. J. Geophys. Res. 1990, 95 (B4), 4453-4470.

673 62. McQuay, E. L.; Torres, M. E.; Collier, R. W.; Huh, C.-A.; McManus, J., Contribution of cold

674 seep barite to the barium geochemical budget of a marginal basin. Deep-Sea Res. 2008, 55

$675 \quad(6), 801-811$.

676 63. McManus, J.; Berelson, W. M.; Klinkhammer, G. P.; Johnson, K. S.; Coale, K. H.;

677 Anderson, R. F.; Kumar, N.; Burdige, D. J.; Hammond, D. E.; Brumsack, H. J.; McCorkle, 
678 D. C.; Rushdi, A., Geochemistry of barium in marine sediments: Implications for its use as a 679 paleoproxy. Geochim. Cosmochim. Acta 1998, 62 (21-22), 3453-3473.

64. Wang, Z.; Shi, Z.; Shi, L.; White, G. F.; Richardson, D. J.; Clarke, T. A.; Fredrickson, J. K.; Zachara, J. M., Effects of soluble flavin on heterogeneous electron transfer between surfaceexposed bacterial cytochromes and iron oxides. Geochim. Cosmochim. Acta 2015, 163, 299310.

65. Michelson, K.; Sanford, R. A.; Valocchi, A. J.; Werth, C. J., Nanowires of Geobacter sulfurreducens require redox cofactors to reduce metals in pore spaces too small for cell passage. Environ. Sci. Technol. 2017, 51 (20), 11660-11668.

66. Enning, D.; Venzlaff, H.; Garrelfs, J.; Dinh, H. T.; Meyer, V.; Mayrhofer, K.; Hassel, A. W.; Stratmann, M.; Widdel, F., Marine sulfate - reducing bacteria cause serious corrosion of iron under electroconductive biogenic mineral crust. Environ. Microbiol. 2012, 14 (7), 17721787.

67. Agarwal, V.; Miles, Z. D.; Winter, J. M.; Eustáquio, A. S.; El Gamal, A. A.; Moore, B. S., Enzymatic halogenation and dehalogenation reactions: pervasive and mechanistically diverse. Chem. Rev. 2017, 117 (8), 5619-5674.

68. Vasileva, D.; Janssen, H.; Hönicke, D.; Ehrenreich, A.; Bahl, H., Effect of iron limitation and fur gene inactivation on the transcriptional profile of the strict anaerobe Clostridium acetobutylicum. Microbiol. 2012, 158 (7), 1918-1929. goethite and hematite by reduced flavins. Geochim. Cosmochim. Acta 2013, 121, 139-154.

70. Steele, J. A.; Countway, P. D.; Xia, L.; Vigil, P. D.; Beman, J. M.; Kim, D. Y.; Chow, C. E. T.; Sachdeva, R.; Jones, A. C.; Schwalbach, M. S.; Rose, J. M.; Hewson, I.; Patel, A.; Sun, F. Z.; Caron, D. A.; Fuhrman, J. A., Marine bacterial, archaeal and protistan association networks reveal ecological linkages. ISME J. 2011, 5 (9), 1414-1425. 
71. Fukunaga, Y.; Kurahashi, M.; Sakiyama, Y.; Ohuchi, M.; Yokota, A.; Harayama, S., Phycisphaera mikurensis gen. nov., sp. nov., isolated from a marine alga, and proposal of Phycisphaeraceae fam. nov., Phycisphaerales ord. nov. and Phycisphaerae classis nov. in the phylum Planctomycetes. J. Gen. Appl. Microbiol. 2009, 55 (4), 267-275.

72. Inagaki, F.; Nunoura, T.; Nakagawa, S.; Teske, A.; Lever, M.; Lauer, A.; Suzuki, M.; Takai, K.; Delwiche, M.; Colwell, F. S., Biogeographical distribution and diversity of microbes in methane hydrate-bearing deep marine sediments on the Pacific Ocean Margin. Proc. Natl. Acad. Sci. U. S. A. 2006, 103 (8), 2815-2820.

73. Harrison, B. K.; Zhang, H.; Berelson, W.; Orphan, V. J., Variations in archaeal and bacterial diversity associated with the sulfate-methane transition zone in continental margin sediments (Santa Barbara Basin, California). Appl. Environ. Microbiol. 2009, 75 (6), 1487-1499.

74. Rodionova, I. A.; Vetting, M. W.; Li, X.; Almo, S. C.; Osterman, A. L.; Rodionov, D. A., A novel bifunctional transcriptional regulator of riboflavin metabolism in Archaea. Nucleic Acids Res. 2017, 45 (7), 3785-3799.

75. Markelova, E.; Parsons, C. T.; Couture, R.-M.; Smeaton, C. M.; Madé, B.; Charlet, L.; Van Cappellen, P., Deconstructing the redox cascade: what role do microbial exudates (flavins) play? Environ. Chem. 2017, 14, 515-524.

76. Liu, C.; Gorby, Y. A.; Zachara, J. M.; Fredrickson, J. K.; Brown, C. F., Reduction kinetics of Fe (III), Co (III), U (VI), Cr (VI), and Tc (VII) in cultures of dissimilatory metal - reducing bacteria. Biotechnol. Bioeng. 2002, 80 (6), 637-649.

77. Ackerley, D.; Gonzalez, C.; Park, C.; Blake, R.; Keyhan, M.; Matin, A., Chromate-reducing properties of soluble flavoproteins from Pseudomonas putida and Escherichia coli. Appl. Environ. Microbiol. 2004, 70 (2), 873-882. 